\title{
Artigo \\ INFLUÊNCIA DA DENSIDADE DO PISTÃO REGENERADOR DO MOTOR STIRLING TIPO GAMA SOBRE A EFICIENCIA TÉRMICA EM UM PROTÓTIPO DE BAIXO CUSTO
}

Pedro Lucas Gomes de Souza Silveira ${ }^{[1]}$, Francisco Edson Nogueira Fraga ${ }^{[2]}$

[1] Universidade Federal Rural do Semiárido; pedrosslucas@ hotmail.com

${ }^{[2]}$ Universidade Federal Rural do Semiárido; nfraga@ ufersa.edu.br

Recebido: 06/07/2020;

Aceito: 09/09/2020;

Publicado: 11/09/2020.

Resumo: Os motores Stirling são máquinas térmicas desenvolvidas com o propósito de gerar potência e energia. Os principais estudos atualmente sobre esses motores se concentram no uso de energias renováveis, limpas ou do reaproveitamento energético de fontes de calor para seu funcionamento. Porém, os motores Stirling também podem ser utilizados para outras aplicações. No presente trabalho, foi realizada a construção de um protótipo de baixo custo de um motor Stirling do tipo gama visando testar seu funcionamento e relacionar propriedades mecânicas e termodinâmicas. Adotou-se um procedimento de ensaio a fim de observar a relação entre a densidade do pistão regenerador e o rendimento energético, em busca de definir um ponto ótimo entre essas duas grandezas. Para as condições testadas no presente trabalho, concluiu-se que a densidade do pistão de $62,45 \mathrm{~kg} / \mathrm{m}^{3}$ permitiu o motor obter o melhor rendimento.

Palavras-chave: Motores Stirling; Ciclo Stirling; Tipo Gama; Regenerador; Eficiência térmica.

Abstract: Stirling engines are thermal machines developed with the purpose of generating power and energy. The main studies on these engines focus on the use of renewable and clean energy or energy reuse as a source of heat for their operation. However, Stirling engines can also be used for other applications. In this present work, the construction of a low-cost prototype Stirling gamma type engine was carried out to discuss the theoretical Stirling cycle and the thermodynamic concepts involved. A test procedure was adopted to observe the relationship between the density of the regenerator and the energy efficiency, to define an optimum point between these two quantities. For the tested conditions in this present work, it was concluded that the piston density of $62.45 \mathrm{~kg} / \mathrm{m}^{3}$ allowed the engine to obtain the best performance.

Keywords: Stirling engines; Stirling cycle; Gamma type; Regenerator; Thermal efficiency.

\section{INTRODUÇÃO}

Em 1815, os irmãos Stirling construíram um primeiro protótipo e o patentearam com o título: "Melhora para Redução do Consumo de Combustível, e em Particular um Motor Capaz de ser Aplicado ao Movimento de Máquina com um Princípio Completamente Novo”.[1] Em sua patente, não só registraram sua máquina, mas também um componente que se tornaria diferencial em seu maquinário, o regenerador, capaz de armazenar calor e utilizá-lo posteriormente como forma de aumentar sua eficiência energética.[2]

Contudo, os motores Stirling com sua construção rigorosa e consumo contínuo de combustível, enfrentaram o desenvolvimento dos motores de combustão interna, de simples fabricação, com combustões reduzidas e controladas do combustível e sua vasta aplicação industrial. Apenas no século seguinte os estudos foram retomados pela empresa holandesa Phillips que passou a implementar motores Stirling em válvulas de rádios em regiões sem acesso à energia elétrica.[3] Atualmente as pesquisas são focadas na geração de energia menos 
poluente e reaproveitamento energético [1], possuindo aplicações desde o desenvolvimento de veículos híbridos a geradores de energia. [4]

Os motores Stirling têm como princípio de geração de energia o bombeamento de calor e, através de seus componentes principais transformam essa injeção de calor em trabalho mecânico. Seus componentes principais são uma câmara quente (também chamada de cilindro quente), uma câmara fria (também chamada de cilindro frio), um pistão de trabalho ou frio, um pistão deslocador ou quente, vasos comunicantes, um volante ou roda de inércia, uma fonte de calor e, podendo ou não, haver um regenerador. [5]

Existem três tipos distintos de motores Stirling, variando entre si de acordo com sua construção, mais especificamente a disposição dos pistões envolvidos nos processos. São eles: o tipo alfa, tipo beta e tipo gama. O Stirling tipo gama (Figura 1) é dotado de dois pistões, assim como os motores do tipo beta, mas possui dois cilindros. No cilindro quente, aquecido pela fonte externa de calor, o fluido de trabalho sofre uma expansão e gera movimento no pistão deslocador. A partir do movimento do pistão, o fluido é forçado ao cilindro frio que cede calor para uma fonte de arrefecimento. No interior do cilindro frio, o gás sofre uma compressão e gera movimento do pistão de trabalho.

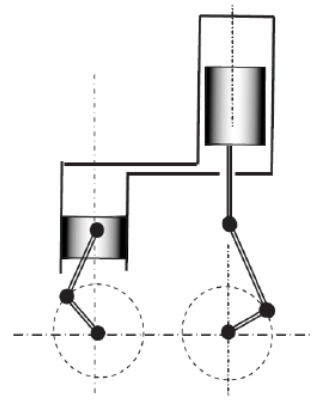

Figura 1. Representação de motor Stirling gama. Fonte [6]

O tipo gama, em comparação aos demais, tem sua disposição e montagem dividida em dois pistões. Esse fato, permite uma maior facilidade na variação de parâmetros como taxa de compressão e área para troca de calor. Em contrapartida, o tipo gama apresenta mais componentes mecânicos, volumes mortos de expansão e compressão maiores e uma perda de potência de saída ocasionada por uma fração da expansão que ocorre no volume de compressão. [6]

Aplicado aos motores Stirling, os regeneradores têm grande relevância e destaque. Seu comportamento característico tem como função intermediar o ciclo entre sua compressão e expansão isotérmica fazendo com que a variação de temperatura e comportamento do fluido de trabalho ocorra a um nível médio que aproxime sua eficiência térmica do rendimento teórico. [7]

Dá-se o nome de regenerador a trocadores de calor empregados em sistemas e componentes termodinâmicos com o objetivo de ora reter calor, ora fornecer calor a esse sistema, de modo a elevar sua temperatura média e, por conseguinte, torná-lo termicamente mais eficiente.

Inicialmente, o fluido que está quente passa pelo regenerador, deixando parte da sua energia térmica. Após seu arrefecimento, o fluido agora frio escoa pela mesma passagem, absorvendo parte do calor deixado anteriormente. A passagem do escoamento do fluido quente através da matriz é denominada hot blow e do fluido frio cold blow. [8]

É importante atentar que esse aumento na temperatura média do sistema, mesmo gerando um ganho na eficiência térmica, ocasiona menores taxas de expansão e compressão do gás. A redução dessas taxas se traduz 
em uma queda na potência gerada que, apesar de não ser quantificada nem amplamente abordada nas literaturas bases, a depender da aplicação do motor no projeto, inviabiliza o uso de regeneradores.

Um parâmetro muito importante no estudo de máquinas térmicas em geral é o seu rendimento e, para tal, precisamos lançar mão de conhecimentos termodinâmicos, ciclos teóricos e teoremas.

O teorema de Schimdt, formulado em 1871, é o instrumento matemático que, levando em consideração transformações isotérmicas de expansão e compressão de um gás ideal, melhor descreve o ciclo Stirling e quantifica o seu rendimento teórico. Apesar de serem considerações que idealizam o cálculo do rendimento, o teorema de Schmidt se aproxima em até $60 \%$ do rendimento real desenvolvido pelo motor analisado.[1]

Observando as transformações de estado ocorridas no ciclo Stirling, o teorema de Schmidt foi capaz de equacionar e deduzir matematicamente o enunciado pelo corolário de Carnot. Esse fato provou sua relevância ao criar uma ferramenta capaz de auxiliar o desenvolvimento e dimensionamento de motores Stirling.

O estudo acerca dos motores Stirling atualmente se focam no desenvolvimento de protótipos e na variação de seus parâmetros de construção e funcionamento. No estudo realizado por [9], essa tendência se torna clara na utilização dos elementos mecânicos mutáveis e se prova relevante principalmente em seu viés científico no entendimento dos ciclos Stirling teórico e prático.

O estudo realizado por [10] também traz à tona esse enfoque, mas com um viés mais prático e focado na geração de trabalho e energia. Através da variação dimensional de um componente específico em seu protótipo, o pistão deslocador, ganhos consideráveis (na faixa de 27\%) de potência e torque foram observados.

Entretanto, a gama de pesquisas relacionadas com a variação da eficiência térmica nos motores Stirling, bem como a influência da variação na densidade do pistão regenerador não são comuns, de forma que ainda pouco se sabe da interdependência entre essas grandezas.

O presente trabalho foi desenvolvido com o objetivo de, a partir da construção de um protótipo de baixo custo de um motor Stirling modelo gama, quantificar a influência da densidade do pistão regenerador sobre o rendimento térmico do protótipo ao relacionar a potência mecânica desenvolvida em razão da potência térmica fornecida pela fonte de calor. Baseado nas literaturas consultadas, é esperada a ocorrência de uma faixa ótima relacionando a densidade do pistão e o rendimento desempenhado sob as condições testadas para que justifique a escolha de um pistão na elaboração de outros projetos semelhantes.

\section{MATERIAIS E MÉTODOS}

Levando em consideração o objetivo de construir um protótipo de baixo custo, foi realizado um estudo sobre os diferentes tipos de motores Stirling, a fim de escolher o modelo que melhor se adequasse às necessidades de construção simplificada com materiais acessíveis, robustez e possibilidade na alteração de seu pistão regenerador. Assim, o tipo escolhido foi o gama. A escolha se deu baseada nas literaturas [7] e [11] que usam como base um protótipo apresentado em [12].

A partir da escolha, foram observadas possíveis limitações e pontos a serem adaptados para que os demais objetivos deste trabalho fossem alcançados. Meios de garantir uma melhor vedação e a fabricação de um pistão regenerador foram os pontos de adaptação e melhoria para que fosse realizada a fabricação e montagem do protótipo apresentado na Figura 2. 


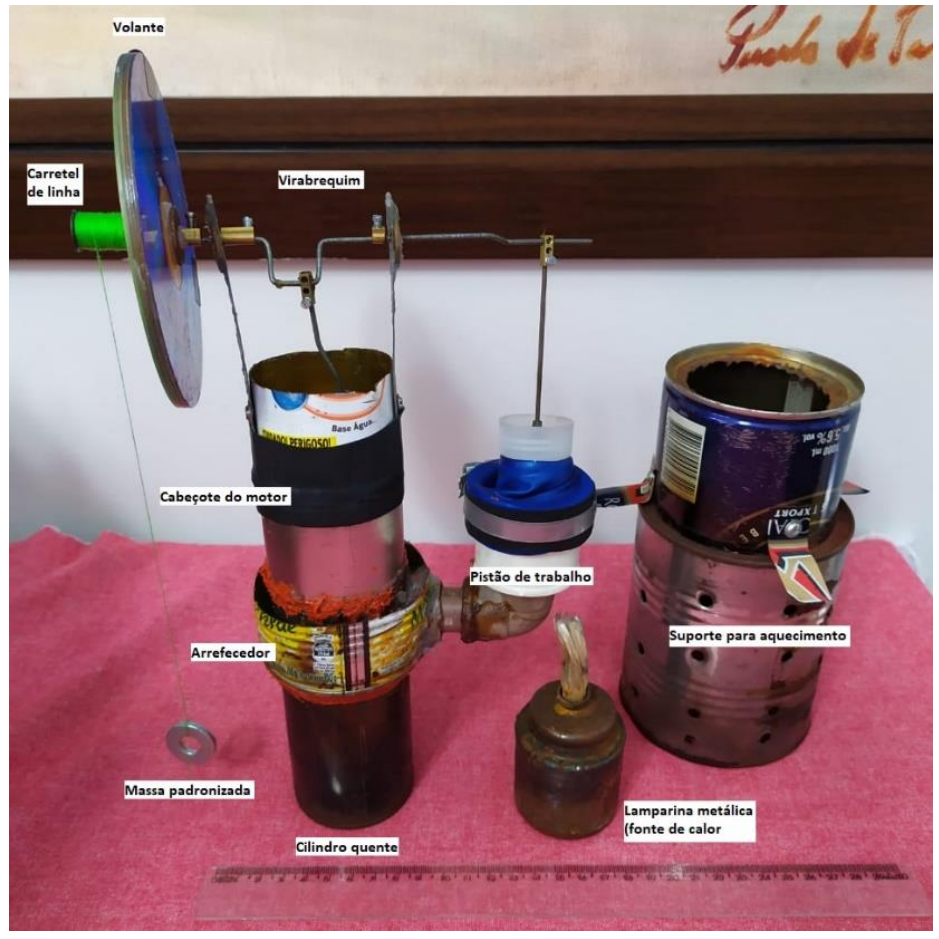

Figura 2. Protótipo construído e principais componentes. (Autoria própria)

Com o objetivo de testar diferentes configurações de densidade para o regenerador, a fim de entender sua influência no funcionamento e rendimento do motor, o pistão regenerador (Figura 3) foi fabricado em material metálico, com furos de diâmetro 11/64" em suas faces superior e inferior para possibilitar a passagem do ar pelo seu interior. Seu volume de $6,97 \cdot 10^{-5} \mathrm{~m}^{3}$ foi quantificado aproximando suas dimensões às de um cilindro. Para torná-lo um pistão regenerador, seu espaço interno foi preenchido com cinco diferentes massas de lã de aço, caracterizando as cinco densidades testadas.

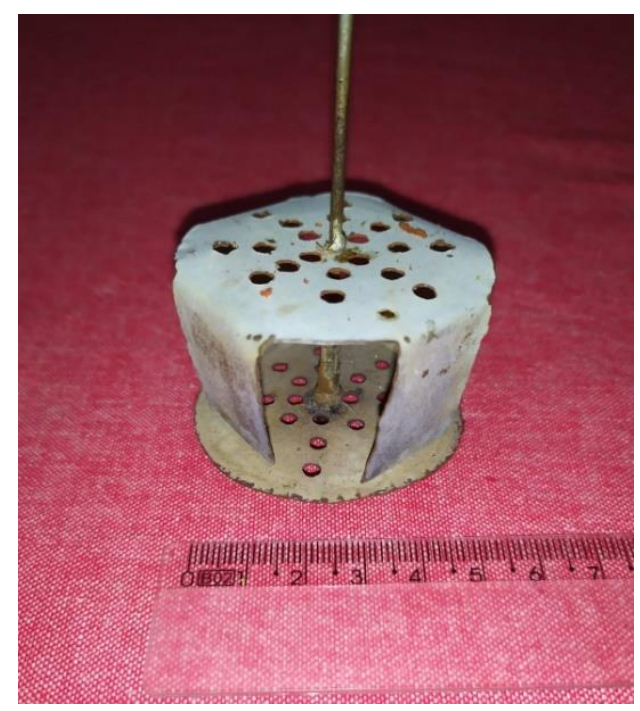

Figura 3. Pistão regenerador. (Autoria própria) 
As massas foram escolhidas observando dois pontos específicos: a) a capacidade volumétrica do pistão, a fim de que toda a massa da lã de aço estivesse contida em seu interior; b) a diferença aproximada de $1 \mathrm{~g}$ entre as massas. As massas usadas foram pesadas com o auxílio de uma balança analítica digital e são apresentadas na Tabela 1 .

Tabela 1: Massas utilizadas nos testes. (Autoria própria)

\begin{tabular}{ccccc}
\hline Massa A & Massa B & Massa C & Massa D & Massa E \\
\hline $1,308 \cdot 10^{-3} \mathrm{~kg}$ & $2,198 \cdot 10^{-3} \mathrm{~kg}$ & $3,006 \cdot 10^{-3} \mathrm{~kg}$ & $4,394 \cdot 10^{-3} \mathrm{~kg}$ & $5,676 \cdot 10^{-3} \mathrm{~kg}$ \\
\hline
\end{tabular}

O virabrequim foi fabricado como indicado em [12], de forma que sua geometria gera um curso de 0,03 $\mathrm{m}$ ao pistão regenerador e 0,022 $\mathrm{m}$ ao pistão de trabalho. Para a fonte de calor foi utilizada uma lamparina metálica abastecida com álcool etílico hidratado $70^{\circ}$ INPM. O fluido arrefecedor escolhido foi a água mineral. Para lubrificação das partes móveis foi utilizada graxa de sabão de lítio LUBRAX Autolith2. Para a vedação foi utilizada cola de silicone para altas temperaturas.

O rendimento teórico foi definido baseado no teorema de Schmidt, sendo as temperaturas do cilindro quente e do cilindro frio medidas com o auxílio de um pirômetro digital. Durante o funcionamento, a temperatura do pistão frio foi de $42,3{ }^{\circ} \mathrm{C}$ e do pistão quente foi de $234,7{ }^{\circ} \mathrm{C}$. Para o cálculo do rendimento experimental do motor foi utilizada a Equação (1).

$$
\eta=\frac{P_{m}}{P_{t}}
$$

Onde $P_{m}$ simboliza a potência mecânica desenvolvida e $P_{t}$ a potência térmica, calculados da seguinte forma:

$$
\begin{gathered}
P_{m}=\frac{W_{m}}{t} \\
P_{t}=\dot{q_{c}} \cdot P C I
\end{gathered}
$$

Em que $W_{m}$ é o trabalho mecânico desenvolvido para levantar um peso padrão a uma determinada altura, e $t$ é o intervalo de tempo em que esse trabalho foi realizado. $\dot{q}_{c}$ é a taxa de consumo de combustível queimado na fonte de calor e $P C I$ o potencial calorífico inferior do combustível.

Para determinação de $W_{m}$, foi acoplado ao volante do motor um carretel de linha de costura e atado ao final da linha uma massa padrão de $0,00848 \mathrm{~kg}$, valor medido com o auxílio de uma balança analítica digital. A altura foi padronizada com uma cota de $0,30 \mathrm{~m}$, medida com o auxílio de uma régua, de modo a ser determinado um trabalho padrão através da Equação 4:

$$
W_{m}=(m g) \cdot H
$$

Em que $m$ é a massa padrão, $g$ a aceleração da gravidade e $H$ a altura padronizada.

Para o cálculo da potência térmica $P_{t}$, inicialmente foi necessário determinar a taxa de consumo de combustível $\dot{q}_{c}$ com o auxílio de uma balança analítica digital. Para isso, a lamparina metálica foi abastecida, pesada e, em seguida, realizada a queima do combustível durante um intervalo de tempo. Após a queima, a lamparina foi novamente pesada e foi determinada a taxa de consumo de combustível igual a $2,2 \cdot 10^{-5} \mathrm{~kg} / \mathrm{s}$. O tempo de queima foi medido usando um cronômetro digital e o PCI do combustível foi obtido através de consulta a tabelas específicas.

Os ensaios foram realizados seguindo a rotina de testes abaixo: 
1. Foi realizado um teste preliminar para garantir o funcionamento correto do motor. Caso aprovado no teste preliminar, o motor seguiria a rotina. Caso reprovado no teste, as condições de vedação e lubrificação do motor eram revisadas e um novo teste preliminar seria realizado. Se o motor não entrasse em funcionamento após o terceiro teste preliminar, a montagem do motor seria refeita. Persistindo o não funcionamento, o pistão regenerador (único parâmetro variado) seria considerado inoperante;

2. A partir da queima do combustível foi acionado o cronometro digital;

3. A lamparina foi posicionada de modo que a chama gerada pela queima do combustível estivesse direcionada à superfície inferior do cilindro quente;

4. A linha foi desenrolada do carretel de modo a permitir o peso padrão descansar sobre uma superfície e um comprimento de linha extra foi desenrolado para garantir que não fosse contada a partida inicial do motor como trabalho realizado;

5. Foi obedecido um tempo de aquecimento de um minuto antes da partida do motor;

6. Foi cronometrado o tempo necessário para a realização do trabalho padronizado;

7. A chama foi extinta e o cronometro parado, marcando o tempo total de queima do combustível.

Foram registrados cinco ensaios válidos para cada densidade do pistão regenerador e esses dados passaram por um tratamento estatístico com auxílio do software Excel.

\section{RESUltados}

O rendimento teórico do motor, calculado utilizando o teorema de Schmidt, é:

$$
\eta=1-t=1-\left(\frac{42,3+273,15}{234,7+273,15}\right)=0,3788
$$

Esse valor traduz o desempenho esperado para o motor caso ele obedeça a todas as considerações e critérios para a dedução do teorema de Schmidt.

A partir das massas apresentadas na Tabela 1 e o volume do pistão, temos que as densidades dos pistões testados foram:

Tabela 2: Densidades dos pistões regeneradores testados. (Autoria própria)

\begin{tabular}{ccccc}
\hline $\begin{array}{c}\text { Densidade do } \\
\text { pistão A }\end{array}$ & $\begin{array}{c}\text { Densidade do } \\
\text { pistão B }\end{array}$ & $\begin{array}{c}\text { Densidade do } \\
\text { pistão C }\end{array}$ & $\begin{array}{c}\text { Densidade do } \\
\text { pistão D }\end{array}$ & $\begin{array}{c}\text { Densidade do } \\
\text { pistão E }\end{array}$ \\
\hline $18,60 \mathrm{~kg} / \mathrm{m}^{3}$ & $31,24 \mathrm{~kg} / \mathrm{m}^{3}$ & $42,73 \mathrm{~kg} / \mathrm{m}^{3}$ & $62,45 \mathrm{~kg} / \mathrm{m}^{3}$ & $80,68 \mathrm{~kg} / \mathrm{m}^{3}$ \\
\hline
\end{tabular}

Com a realização dos ensaios, foram registrados os seguintes valores de rendimento medido:

Tabela 3: Rendimentos médios

medidos. (Autoria própria)

\begin{tabular}{ccccc}
\hline Pistão A: & Pistão B & Pistão C & Pistão D & Pistão E \\
\hline- & $0,1165\left(10^{-4}\right)$ & $0,1304\left(10^{-4}\right)$ & $0,2224\left(10^{-4}\right)$ & $0,1331\left(10^{-4}\right)$ \\
\hline
\end{tabular}


O Pistão A não foi aprovado no teste preliminar, por isso foi considerado inoperante e o rendimento não pôde ser medido com essa configuração.

O rendimento medido apresentou valores ínfimos se comparados ao rendimento teórico esperado, de forma a não fazer sentido a comparação entre valores teóricos e medidos. Uma discrepância já era esperada pelo caráter idealizado com que o rendimento teórico foi determinado (fluido modelado como gás ideal, transformações isotérmicas e isocóricas, confinamento perfeito do fluido de trabalho, pressões mínimas e máximas, volumes de expansão e compressão bem definidos), porém a diferença de comportamento observada extrapola as diferenças causadas pela idealização. Como causa dessa maior diferença pode ser considerada a simplicidade na construção do protótipo, responsável por gerar fugas incontroláveis do fluido de trabalho, folgas entre as partes móveis, pressões de trabalho inferiores às requeridas e até o desbalanceamento do volante.

$\mathrm{Na}$ Figura 4 está representado o gráfico relacionando o rendimento medido $\left(\eta_{m}\right)$ e densidade do pistão regenerador $(\rho)$ com base nos resultados obtidos.

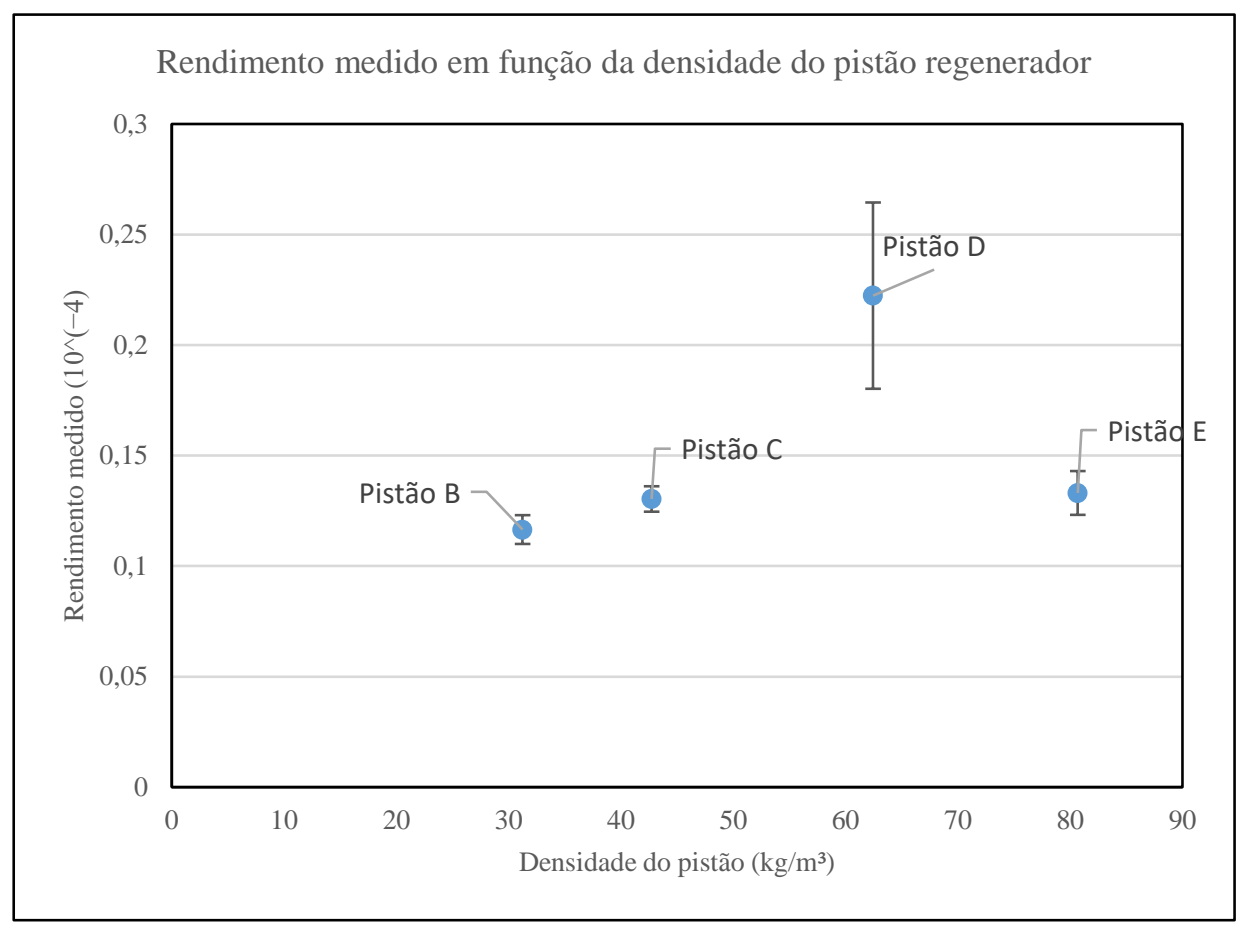

Figura 4. Gráfico Rendimento medido x Densidade do pistão. (Autoria própria)

Foi possível observar um comportamento que relaciona as grandezas observadas no gráfico da Figura 4. Pode-se perceber uma tendência no aumento do rendimento até uma faixa aproximada à da densidade do Pistão D. Esse comportamento pode sugerir que, apesar de cumprir sua função de gerar uma temperatura média de operação mais elevada como pistão regenerador, densidades inferiores à do Pistão D podem permitir a passagem de uma maior fração de ar por seu interior, gerando uma perda na taxa de compressão e consequentemente uma perda de potência.

Observando o comportamento do Pistão E nessas condições de aplicação, o gráfico sugere uma tendência de queda no rendimento do motor, indicando assim que o aumento demasiado na densidade do pistão regenerador a partir da faixa observada no Pistão D tende a gerar um comportamento que se assemelha a de um pistão sólido, baseado na discussão de [6]. Esse comportamento sugere o aparecimento de um gradiente de temperaturas mais elevado e faz com que o motor necessite de uma quantidade maior de calor para seu 
funcionamento, reduzindo sua eficiência térmica.

\section{CONCLUSÃO}

O protótipo construído a partir da reutilização de materiais permitiu a visualização prática do funcionamento do ciclo Stirling, a compreensão acerca de um motor de combustão externa e o seu desempenho em condições específicas de trabalho.

É possível utilizar o protótipo construído para discussão de conceitos termodinâmicos tais como transformações isotérmicas, caracterizadas por alterações nas propriedades de estado (pressão e volume) de uma quantidade de gás ocorrendo a faixas de temperatura constante, e transformações isocóricas, caracterizadas por transformações que alteram as propriedades de estado (temperatura e pressão) de uma quantidade de gás ocorrendo a volumes constantes.

O modelo se mostrou viável para observar uma influência da densidade do pistão regenerador sobre o rendimento térmico do motor. Para as condições especificas estudadas aqui, foi observado que, na faixa de $18,60 \mathrm{~kg} / \mathrm{m}^{3}$ (Pistão A), o motor não foi capaz de gerar o trabalho padrão definido. Acima dessa faixa, entre $31,24 \mathrm{~kg} / \mathrm{m}^{3}$ e $62,45 \mathrm{~kg} / \mathrm{m}^{3}$ (faixa compreendendo do Pistão B ao Pistão D), o rendimento do motor apresentou uma tendência crescente. Da faixa entre $62,45 \mathrm{~kg} / \mathrm{m}^{3}$ e $80,68 \mathrm{~kg} / \mathrm{m}^{3}$ (faixa de densidade compreendendo do Pistão D ao Pistão E), o rendimento do motor apresentou uma tendência decrescente em função do aumento da densidade do pistão.

Os ensaios realizados mostram que essa relação entre densidade do pistão regenerador e eficiência térmica tendem a quantificar um ponto ótimo nessa relação. Para as condições de montagem, trabalho padrão e calor fornecido adotadas neste trabalho, o ponto ótimo se encontra por volta do valor de $62,5 \mathrm{~kg} / \mathrm{m}^{3}$ (Pistão D). Para outras condições e montagens, esse ponto ótimo pode variar sugerindo assim um estudo mais aprofundado quanto a influência dessa grandeza em condições diferentes.

\section{AGRADECIMENTOS}

Ao Laboratório de Ensaios Mecânicos da Universidade Federal Rural do Semiárido por disponibilizar suas instalações para realizarmos as medições necessárias para a realização dos procedimentos metodológicos desenvolvidos.

\section{REFERÊNCIAS}

[1] PAUTZ, Edson Ronaldo. Estudo e Projeto de Um Motor Stirling. Universidade Regional do Noroeste do Estado do Rio Grande do Sul: Panambi, 2013.

[2] DEYÁ, Alejandro Diáz. BARRIO, Rodrigo Pinedo Del. Propuesta de diseño de um motor Stirling de pistón libre tipo Tándem para uso doméstico. Universidade Nacional Autónoma de México. México, D.F.2014.

[3] MARTINI, W. R. Stirling engine design-manual second edition. Honolulu: University Press of the Pacific,1983;

[4] VIDAL, Felipe Salvador; LIMA, Manoel Neves. Funcionamento e Aplicação de Motores Stirling em Veículos Híbridos. 2014. Trabalho de Conclusão de Curso (Graduação em Eletrônica Automotiva) - Fatec Santo André, Santo André, 2014.

[5] ARAÚJO, Liliane Ferreira. Desenvolvimento experimental de um protótipo do motor Stirling modelo alfa. 2017. Projeto de conclusão de curso (Graduação em Engenharia Mecânica) - Universidade Federal Rural do Semiárido, Mossoró, 2017. 
[6] CRUZ, Vinícios Guimarães da. Desenvolvimento Experimental de Um Motor Stirling Tipo Gama. Dissertação de Mestrado. Universidade Federal da Paraíba: João Pessoa, 2012.

[7] DE ASSIS COSTA, Ítalo Rodrigo Nunes; MARTINS, Mônica Veras; DUARTE, João Batista Furlan. Construção e análise teórica e experimental de um motor Stirling tipo gama.

[8] SOUSA, Lereno Ilavoco Mata de. Estudo do desempenho de um regenerador para um motor de Stirling. 2009. Tese de Doutorado. Universidade da Beira Interior.

[9] CRESTANI, Marcelo Henrique. Projeto e construção de um motor Stirling do tipo gama com elementos mecânicos mutáveis. 2016. 143 f. Trabalho de Conclusão de Curso (Graduação) - Universidade Tecnológica Federal do Paraná, Pato Branco, 2016.

[10] CAETANO, Bryan Castro. Estudo da influência das dimensões do pistão deslocador nos parâmetros de desempenho de um motor Stirling do tipo beta. Acta Mechanìca et Mobilitatem, v. 2, n. 4, p. 20-26, 2018.

[11] MELO, Diandra Caroline Xavier Silveira de. Motor Stirling como ferramenta de auxílio no aprendizado da Termodinâmica. 2019. 11f. Trabalho de Conclusão de Curso (Graduação em Engenharia Mecânica) - Centro de Tecnologia, Departamento de Engenharia Mecânica, Universidade Federal do Rio Grande do Norte, Natal, 2019.

[12] WAGNER, Leandro. Manual do motor Stirling. Vale do Rio Pardo, RS, 2011. Disponível em: http://manualdomotorStirling.blogspot.com/. Acesso em: 10 maio 2019. 